\title{
Palliation of malignant dysphagia: surgery, radiotherapy, laser, intubation alone or in combination?
}

Until relatively recently almost all discussions of the management of cancers of the oesophagus and gastric cardia centred around striving for maximum survival time. ${ }^{12}$ Now it is recognised that as few of these tumours can be cured it is just as important to provide effective palliation for dysphagia with minimum morbidity. ${ }^{3-5}$ The morbidity of any procedure undertaken must be balanced with the likely benefits for each patient, in terms of both the relief of dysphagia and prolonging survival. The choice of procedure depends on the age and general condition of the patient together with the stage of their cancer. The main options are surgery, radiotherapy, chemotherapy, and a range of endoscopic techniques, of which the most important are laser treatment and insertion of a prosthesis.

The relevant questions are: How effectively will dysphagia be relieved and how long will it take? What is the procedure related morbidity and mortality? How long will the palliation last and is further treatment possible for recurrence?

Many of these questions have been answered at least in part over the past few years, although there has been a tendency for the proponents of particular techniques to focus on their merits without controlled comparisons with alternative strategies for the same patient groups. Surgeons, radiotherapists, and endoscopists often identify patient groups and assess the results of treatment in ways which make a direct comparison between them difficult. This is now recognised and attempts are being made to rectify the problem. The real advances of the last few years, however, have come from assessing the merits of various combinations of techniques. The number of permutations is large particularly when account is taken of the range of ways in which each technique can be used. Most work has been done on the combination of radical external beam radiotherapy and surgery, with or without additional chemotherapy. In general, where comparisons are possible, appropriately selected patients treated with combined regimens have lived longer than those given one form of treatment, but the ordeal for the patient is often considerable, and often not well documented. In general, endoscopic techniques have been used on their own for the patients in poor general condition with more advanced tumours where the main aim is rapid relief of dysphagia with minimum morbidity.

For patients treated either radically or palliatively, documentation of the relief of dysphagia is often poor. Table I summarises data from studies of each technique used on its own in the management of advanced malignant dysphagia in an attempt to answer these questions (F C A Den Hartog Jager, G N J Tytgat, personal communication). ${ }^{1+19}$ No appropriate data are available for chemotherapy as the only therapy. The patient groups selected in each paper are different and information was often not available in the same form for each technique. Sometimes it was necessary to extrapolate from the published data to provide the figures used here, and where this could not be done with confidence the figures are omitted from the table. The results provide a reasonable data base for a discussion of the available options. Interpretation of the data on quality of swallowing is difficult since authors interpret the concept of normal swallowing in different ways. Comparisons can only be made effectively when the quality of swallowing is assessed by the same individuals for different techniques in a controlled manner. ${ }^{5}$

The regimens used in the multitreatment programmes aimed at extending survival are complicated. It is beyond the scope of this article to try to establish how the degree of dysphagia varies through the treatment period, and how long it is from the start of treatment before patients feel generally as well as they did before treatment started. For some

TABLE I Comparison of the efficacy and morbidity of techniques used as sole treatment for palliation of malignant dysphagia

\begin{tabular}{|c|c|c|c|c|c|}
\hline & Surgery & $\begin{array}{l}\text { External } \\
\text { radiotherapy }\end{array}$ & Brachytherapy & Tube & Laser \\
\hline $\begin{array}{l}\% \text { of patients with improved } \\
\text { swallowing after initial } \\
\text { treatment }\end{array}$ & 100 & $70-90$ & $75-95$ & 100 & 80 \\
\hline $\begin{array}{l}\% \text { of patients eating solids } \\
\% \text { of patients eating } \\
\text { semi-solids }\end{array}$ & $\begin{array}{l}90 \\
10\end{array}$ & $\begin{array}{l}50 \\
22\end{array}$ & $\begin{array}{l}50 \\
35\end{array}$ & $\begin{array}{l}10-50^{\star} \\
50-70\end{array}$ & $\begin{array}{l}35-85 \\
55\end{array}$ \\
\hline $\begin{array}{l}\text { Time from start of therapy } \\
\text { to best effect (weeks) }\end{array}$ & 3 & 6 & 1, & 0 & 1 \\
\hline $\begin{array}{l}\text { Procedure related } \\
\text { mortality }(\%)\end{array}$ & $10-30$ & $0-2$ & 0 & $0-8$ & $0-1$ \\
\hline $\begin{array}{l}\text { Complications of initial } \\
\text { procedure }(\%)\end{array}$ & 35 & $10-30$ & $10-30$ & $5-15$ & $2-4$ \\
\hline $\begin{array}{l}\text { \% of patients needing } \\
\text { further treatment }\end{array}$ & 20 & $30-50$ & 30 & 35 & $70-95$ \\
\hline $\begin{array}{l}\text { Average time before } \\
\text { further treatment (weeks) }\end{array}$ & $5-50$ & $10-40$ & $10-30$ & 20 & 6 \\
\hline
\end{tabular}

*With non-standard tubes, this figure can rise to $100 \%$.

Note: The data are derived from all the references given in this paper. As many of the data in the original papers were not available in the required form, all figures should be regarded as approximate. Where there was reasonable agreement should be regarded as approximate. Where there was reasonable agreement between different authors a single figure is given, but where there was wide discrepancy a range is given. The patient groups often differed between series, almost no data come from controlled studies, and in many series at least some of patients had more than one type of treatment. Nevertheless, the table gives a
general comparison of the most important aspects for each treatment modality. 
regimens, however, considerable morbidity may continue for many weeks and this must be remembered when considering the patients' quality of life. Even when cure is not feasible treatment options for patients with advanced disease may be divided into two broad categories - radical treatment that aims to eradicate as much as possible of the main tumour bulk and palliative treatment that attempts to remove the intraluminal tumour that is causing dysphagia and slow down local regrowth.

\section{Techniques that treat all the primary cancer}

\section{SURGERY}

In Table I the time from treatment to optimum therapeutic response for patients treated by resection is taken as the average hospital stay, using the assumption that these patients were able to swallow satisfactorily on discharge. Many, however, had thoracoabdominal procedures and one would expect a period of at least two to three months after surgery before their general activity was back to normal. This is acceptable for patients with a reasonable prognosis but of doubtful value for those with a poor prognosis. Even if all macroscopic tumour is removed a fibrous stricture or a local recurrence may develop at the anastomosis. Palliative bypass surgery has been largely superseded by less invasive, nonsurgical techniques. ${ }^{6}$

\section{RADIOTHERAPY}

Most data on external beam radiotherapy for oesophageal cancer comes from an era when the main aim of treatment was to prolong survival. In most series the patients treated were unsuitable for surgery, but despite this survival times are comparable to those for patients treated by surgery. Earlam and Cunha-Melo open their comprehensive review of 1980 with the statement that there had been no controlled trial of radiotherapy $v$ surgery for squamous cell carcinoma of the oesophagus. ${ }^{2}$ This deficiency has still not been rectified. Few publications focus on the effect of radiotherapy on dysphagia. Caspars $e t a l^{4}$ conclude that patients with minor degrees of dysphagia benefit most from high dose radiotherapy, but that those unable to swallow even semi-solids gain little from high or low dose radiotherapy and are more appropriately treated by other means such as intubation or laser treatment.

Two other factors should be taken into account when assessing the results of radiotherapy. Up to $20 \%$ of patients who start a radical course of radiotherapy are unable to complete it due to poor tolerance of treatment. ${ }^{8}$ The planned radical course is thus reduced to a palliative course. Even if a planned course can be completed, side effects from the radiation, either localised oesophagitis or a more general malaise, may persist, sometimes for the remainder of the patient's life. This is poorly documented in publications but may detract greatly from the quality of palliation achieved. The other factor relates to the time scale of the response. A course of treatment may spread over two to six weeks and it is often difficult to determine the interval from the start of treatment until the maximum improvement in dysphagia is seen. Dysphagia may deteriorate at any time during treatment, but is typically worst at five days after starting treatment and then improves over a period of weeks. ${ }^{10}$ There are no published data with a detailed analysis of how the dysphagia grade changes with time during and after treatment for individual patients. Yet another aspect is the frequently repeated statement that squamous carcinomas respond to radiotherapy better than adenocarcinoma, but two studies that compared the outcome showed no difference in response. ${ }^{20}$

\section{CHEMOTHERAPY}

Chemotherapy tackles the entire tumour bulk, but it is not clear how dysphagia is modified after chemotherapy alone. ${ }^{21}$

Techniques for relieving dysphagia by reducing the bulk of tumour in the oesophageal lumen

\section{INTUBATION}

Insertion of a prosthesis through an obstruction due to an oesophageal cancer achieves maximum relief of dysphagia immediately, particularly if the procedure is carried out endoscopically. The disadvantage is that all food must pass through a rigid tube. In most series commercially available tubes of internal diameter $10-11 \mathrm{~mm}$ have been used, this means that only $10-15 \%$ of patients can eat a diet that is anywhere near normal, although using the larger individually prepared Tygon tubes this figure can be increased considerably. ${ }^{16}$ Once a tube is in place the quality of swallowing is usually similar for many months. Some tubes become displaced and others obstructed by food impaction or tumour overgrowth, but these problems can usually be overcome by further endoscopic procedures to reposition or disimpact the tube.

\section{LASER}

Laser recanalisation of obstructing oesophageal cancers with the high power neodymium yttrium-aluminium-garnet (NdYAG) laser was first described in 1982. ${ }^{22}$ Since then, many groups have reported high initial success rates with few complications. ${ }^{16-19}$ The quality of swallowing after laser treatment is much more variable than after intubation. Typically, a third of patients can take a normal diet, and a further $50-60 \%$ some solids or semi-solids. The full benefit is seen within a few days of treatment, but the disadvantage is that regrowth of tumour in the oesophageal lumen may necessitate regular treatments during follow up. Most authors recommend treatments at intervals of four to six weeks to prevent recurrent dysphagia. Such treatments can be done as day case procedures - acceptable for patients whose general condition is good but unsuitable for those in poor general condition from disseminated malignancy. Should laser treatment be unsuccessful either initially or at any time during the follow up period, a tube can normally be inserted.

\section{OTHER ENDOSCOPIC TECHNIQUES}

Simple dilatation can relieve obstruction temporarily to improve access for insertion of a prosthesis or for other endoscopic treatment but seldom provides useful palliation for more than a few days.

Electrocoagulation can be used to recanalise oesophageal cancers by passing bipolar probes over a guide wire into the tumour under radiological control. The intraluminal tumour bulk is reduced by local coagulation. This is effective for large, circumferential lesions but cannot be carried out under direct vision and has a higher complication rate than laser treatment. ${ }^{23}$

Tumour bulk can be reduced by endoscopic injection of ethanol. Necrosed tissue sloughs within a few days. The short and long term results are similar to laser treatment (on the limited data available), complications are rare, and the cost minimal. ${ }^{2+}$ For bulky polypoid lesions this could prove a simple, readily available option, but it is difficult to be sure just where the alcohol is going once it enters the tissue, as has been shown in studies injecting alcohol into liver tumours, so the technique is less precise than laser treatment. ${ }^{25}$ 
TABLE II Six month and one year survival for laser, intubation, and brachytherapy with and without external beam irradiation

\begin{tabular}{|c|c|c|c|c|}
\hline & \multicolumn{2}{|c|}{ Monotherapy (\%) } & \multicolumn{2}{|c|}{$\begin{array}{l}\text { Combined with extermal } \\
\text { beam radiotherapy }(\%)\end{array}$} \\
\hline & 6 months & 1 year & 6 months & 1 year \\
\hline $\begin{array}{l}\text { Laser } \\
\text { Intubation } \\
\text { Brachytherapy }\end{array}$ & $\begin{array}{l}36 \\
13 \\
40\end{array}$ & $\begin{array}{r}9 \\
7 \\
10\end{array}$ & $\begin{array}{l}60 \\
52 \\
75\end{array}$ & $\begin{array}{l}32 \\
11 \\
25\end{array}$ \\
\hline
\end{tabular}

Note: None of these comparisons comes from controlled trials. The laser series come from consecutive studies in a similar patient population from the same department. ${ }^{30}$ The survival times for intubation as monotherapy are lower than in department. ${ }^{30}$ The survival times for intubation as monotherapy are lower than
most series but are used here as a comparison was available with patients given radiotherapy in the same unit. ${ }^{31}$ The figures for brachytherapy with and without external irradiation come from different departments, but using similar treatment regimens. $1: 1332$

\section{BRACHYTHERAPY}

Intracavitary irradiation is attracting considerable interest with the development of instruments such as the Selectron remote control afterloading machine, as it makes the procedure simpler, faster, and safer for staff. The data available for its efficacy as sole treatment in the management of oesophageal tumours is limited (F C A Den Hartog Jager, G $\mathrm{N}$ J Tytgat, personal communication), ${ }^{12}{ }^{13}$ but the relief of dysphagia is much faster than after external beam therapy. There is a risk of troublesome and persistent oesophagitis in up to $30 \%$ of cases (F C A Den Hartog Jager, G N J Tytgat, personal communication) and in combination with external beam therapy this can rise to $100 \% .^{26}$ One group has, however, reported an incidence as low as $3 \% .^{13}$

The quality of swallowing is most consistent after insertion of a prosthesis, although it is surprising how much variation is reported between series. It is difficult to believe that anyone with a prosthetic tube in place eats an entirely normal diet. Swallowing is much more variable after laser treatment, but a good laser result really does mean taking a normal diet. The outcome after brachytherapy probably comes somewhat between these two in terms of function. Laser treatment has the lowest incidence of complications but requires the highest number of treatments, typically two to three treatments for initial recanalisation and then repeat treatments every four to six weeks (Table I).

\section{Discussion}

With this information is it possible to determine the most appropriate treatment for each patient not considered suitable for a radical multitreatment approach?

Complete surgical removal of a primary tumour provides the best relief of dysphagia, but the morbidity and mortality are normally too high when this is done as a palliative procedure. Current diagnostic techniques, particularly computed tomography, abdominal ultrasonography, and endoscopic ultrasonography, now identify many patients with extensive disease in whom curative surgery is no longer an option, which has reduced the number of patients submitted to surgery. ${ }^{6}$

For a patient whose general condition is poor, insertion of a prosthesis as a one stage procedure with low morbidity improves swallowing, although the diet rarely returns to normal. The lumen through the tumour is fixed for the remainder of the patient's life and other measures are unlikely to influence the grade of dysphagia. ${ }^{1+}$

Uncertainty exists in the majority of patients, who present between these two extremes. The first priority for the patient is rapid relief of dysphagia. Most tumours have a major intraluminal component. Debulking can be achieved by any of the endoscopic techniques or with brachytherapy. The laser has the considerable advantages of more accurate tumour ablation, under direct vision, and part of the tumour mass can usually be vaporised during treatment, giving immediate benefit. Brachytherapy with the Selectron gives a circumferential effect and may be less appropriate for a tumour where the main bulk is confined to one side of the oesophagus, as this could lead to high doses of irradiation on normal areas and may explain the relatively high incidence of persistent oesophagitis. This could be overcome by inserting radioactive gold seeds into the tumour bulk endoscopically, but the advantages of the ease of use of the Selectron would be lost. Brachytherapy also has the disadvantage that repeat treatments are limited by the problem of cumulative toxicity and the tissues left behind after healing are radiation damaged. The laser effect is purely thermal, so what is left after healing of any damage to normal areas is regenerated normal mucosa or normal fibrous tissue, ${ }^{27}$ and any further tumour growth in the same area can be treated again with the laser safely as often as required. Similar healing would be expected after electrocoagulation and alcohol injection. The time after treatment before further intervention is required for dysphagia is usually longer after brachytherapy (Table I). It seems logical to use the laser when there is asymmetry or obvious tumour bulk protruding into the lumen of the oesophagus and brachytherapy when the tumour is less protruberant and roughly cylindrical in shape.

Debulking of intraluminal tumour by these means has little influence on tumour tissue infiltrating beyond the oesophageal wall, although if the intraluminal bulk is small, brachytherapy may produce a deeper effect. The average survival for patients treated by intubation, laser treatment, or brachytherapy alone was similar and typically five to six months. ${ }^{512-19}$

Longer palliation and perhaps even longer survival might be achieved if growth in the deeper areas could be slowed by external beam radiotherapy. Caspars et al showed that relief of dysphagia by external beam radiotherapy alone is relatively slow and works better for those with mild dysphagia. ${ }^{4}$ Thus a logical approach would be to combine intraluminal debulking with external beam radiotherapy. Few data are available on such combinations.

Bader et al combined initial laser treatment with subsequent brachytherapy and external beam therapy and showed a longer period of palliation than would be expected after laser alone, but it was not clear which form of radiotherapy was providing the benefit. ${ }^{28}$ Hagenmuller et al carried out a controlled trial comparing laser with laser plus brachytherapy. There was a small increase in the duration of palliation with the combination and a small increase in survival. ${ }^{29}$ This suggests that much of the added benefit in the Bader trial came from the external beam therapy rather than the brachytherapy. We have carried out a pilot study of laser treatment followed by palliative external irradiation on 22 patients. ${ }^{30}$ Preliminary results suggest that the average time between follow up laser endoscopies rose to 16 weeks (comparable to that after brachytherapy), and there was a trend towards longer survival compared with similar patients treated by laser alone (seven of $22,(32 \%)$, survived one year compared with four of $43(9 \%)$ in a comparable group treated with laser alone). Most studies of combined treatment have used an external beam dose of at least $40 \mathrm{~Gy}$, although in our small series those treated with a dose of $30 \mathrm{~Gy}$ did better than those given higher doses with few side effects associated with the ionising radiation. The patients in our series were being treated primarily for palliation, so would have been in a worse general condition and less able to tolerate the higher doses. The survival data available comparing recanalisation techniques alone and in combination with external radiotherapy are summarised in Table II..$^{512} 13$ 30-32 
It seems that these simple combination treatment regimens might improve the survival time for at least some of these incurable patients, particularly those where the tumour is mainly localised to the area of origin, although care must be taken to ensure that the irradiation dose is not high enough to cause appreciable toxicity. For laser patients it may reduce the number of follow up endoscopies required to a similar level to those needed after intubation or brachytherapy while maintaining the other advantages of laser treatment (good quality of swallowing and low incidence of endoscopic complications). These tentative conclusions must be tested in controlled trials. Such a trial of laser $v$ laser plus external irradiation has started and a similar study should compare intubation and brachytherapy with and without external irradiation. These trials must be conducted with care to document the quality of swallowing on a standardised scale at regular intervals on every patient, the date of every invasive procedure, and the general condition of the patient, particularly during and in the first few weeks after external irradiation.

When the best combination of endoscopic treatment and ionising radiation has been identified there is still the question of whether chemotherapy has any part to play in patients with advanced cancers. The toxicity of most current chemotherapy agents makes it unlikely that they will have a major role in palliative regimens.

The optimum management for patients with advanced malignant dysphagia is not yet established, although progress is being made. It is most important that the aims of treatment for each patient are identified realistically (cure, maximum survival time, or palliation of dysphagia). The benefits and complications of each treatment option must be understood for each group of patients before any conclusions are drawn or any attempt is made to combine treatments. For the patients with advanced disease we now appreciate what surgery, external irradiation, brachytherapy, laser treatment, and intubation can offer on their own. A combination of two or more treatments will probably be best for most patients, but this must be proved in controlled studies. The best results come from centres treating large numbers of patients, making it feasible to complete trials comparing the various treatment options in as short a time span as possible. Referral of suitable patients to centres with this specialist interest should be encouraged.

For most patients with advanced squamous carcinomas or adenocarcinomas causing dysphagia, laser or brachytherapy followed by palliative external beam radiotherapy looks the most promising approach, with endoscopic intubation as the fallback position if the results are not satisfactory either initially or during the follow up period.

S G BOWN

National Medical Laser Centre,

The Rayne Institute,

5 University Street,

London WCIE 677, UK

1 Earlam RJ, Cunha-Melo JR. Oesophageal squamous cell carcinoma. I A Critical review of surgery. Br $\mathcal{F}$ Surg 1980; 67: 381-90.
2 Earlam R, Cunha-Melo JR. Oesophageal squamous cell carcinoma: II A critical review of radiotherapy. Br $\mathcal{F}$ Surg 1980; 67: 457-61

3 Watson A. A study of the quality and duration of survival following resecton, endoscopic intubation and surgical intubation in oesophageal carcinoma Br F Surg 1982; 69: 585-8.

4 Caspars RJL, Welvaart K, Verkes RJ, Hermans J, Leer JWH. The effect of radiotherapy on dysphagia and survival in patients with esophageal cancer. Radiother Oncol 1988; 12: 15-23.

5 Loizou LA, Grigg D, Robertson C, Atkinson M, Bown SG. Endoscopic palliation for malignant dysphagia: a prospective comparison of laser therapy palliation for malignant dysphagia: a prospective com

6 Watson A. Surgery for carcinoma of the oesophagus. Postgrad Med F 1988; 64 : $860-4$.

7 Jackson JW, Cooper DKC, Guvendik L. The surgical management of malignant tumours of the oesophagus and cardia: a review of the results in 292 patients treated over a 15 year period. Brf Surg 1979; 66: 98-104.

8 Wara WM, Mauch PM, Thomas AN, Phillips TL. Palliation for carcinoma of the esophagus. Radiology. 1976; 121: 717-20.

9 Pearson JG. The value of radiotherapy in the management of squamous oesophageal cancer. Br f Surg 1971; 58: 794-8.

10 Pearson JG. Present status and future potential of radiotherapy in the management of oesophageal cancer. In: Silber F, ed. Carcinoma of the oesophagus. Rotterdam: Balkema, 1978: 334-9.

11 Newaishy GA, Read GA, Duncan W, Kerr GR. Results of radical radiotherapy of squamous cell carcinoma of the oesophagus. Clin Radiol 1982; of squamo $347-52$.

12 Rowland CG, Pagliero KM. Intracavitary irradiation in palliation of carcinom of oesophagus and cardia. Lancet 1985; ii: 981-3.

13 Pagliero KM, Rowland CG. Brachytherapy for inoperable cancer of the esophagus and cardia. In: Delarue NC, Wilkins EW, Wong J, eds. Intermational trends in general thoracic surgery. Vol 4. St Louis MO: Mosby, 1988: 361-7.

14 Ogilvie AL, Dronfield MW, Ferguson R, Atkinson M. Palliative intubation of oesophagogastric neoplasms at fibreoptic endoscopy. Gut 1982; 23: 1060-7.

15 Gasparri G, Casalegno PA, Camandona M, et al. Endoscopic insertion of 248 prostheses in inoperable carcinoma of the esophagus and cardia: short-term and long-term results. Gastrointest Endosc 1987; 33: 354-6.

16 Buset M, des Marez B, Batze M, et al. Palliative endoscopic management of obstructive esophagogastric cancer: laser or prosthesis? Gastrointest Endosc 1987; 33: 357-61

17 Krasner N, Barr H, Skidmore C, Morris AI. Palliative laser therapy for malignant dysphagia. Gut 1987; 28: 792-8.

18 Ell C, Riemann JF, Lux G, Demling L. Palliative laser treatment of malignant stenoses in the upper gastrointestinal tract. Endoscopy 1986; 18 (suppl 1): 21-6.

19 Mellow M, Pinkas H. Endoscopic laser therapy for malignancies affecting the esophagus and gastroesophageal junction. Analysis of technical and functional efficacy. Arch Intern Med 1985; 145: 1443-6.

20 Cederqvist $C$, Nielsen J, Berthelsen A, Sand Hansen H. Cancer of the oesophagus: II. Therapy and outcome. Acta Chir Scand 1978; 144: 233-40.

21 Poplin E, Fleming T, Leichman L. Combined therapies for squamous cell carcinoma of the esophagus, a southwest oncology group study (SWOG8037). F Clin Oncol 1987; 5: 622-8.

22 Fleischer D, Kessler F, Haye O. Endoscopic NdYAG laser therapy for carcinoma of the esophagus: a new palliative approach. Am $\mathcal{F}$ Surg 1982; 143: $280-3$.

23 Johnston JH, Fleischer D, Petrini J, Juergen Nord H. Palliative bipolar electrocoagulation therapy of obstructing esophageal cancer. Gastrointest Endosc 1987; 33: 349-53.

24 Payne-James JJ, Spiller RC, Misiewicz JJ, Silk DBA. Use of ethanol-induced tumor necrosis to palliate dysphagia in patients with esophagogastric cancer. Gastrointest Endosc 1990; 36: 43-6.

25 Van Eyken P, Hiele M, Severy J, Gebboes K, Van Trappen G, Penninckx F, et al. Comparative study of low power Nd: YAG laser interstitial hyperthermia versus ethanol injection for controlled hepatic tissue destruction. Lasers in Medical Science 1991; 6: 35-41.

26 Hishikawa Y, Tanaka S, Miura T. Esophageal ulceration induced by intracavitary irradiation for esophageal carcinoma. Am 7 Radiol 1984; 143. 269-73.

27 Bown SG, Hawes R, Matthewson K, et al. Endoscopic laser palliation for advanced malignant dysphagia. Gut 1987; 28: 799-807.

28 Bader M, Dittler HJ, Ultsch B, Ries G, Siewert JR. Palliative treatment of malignant stenoses of the upper gastrointestinal tract using a combination of malignant stenoses of the upper gastrointestinal tract using a combinat

29 Hagenmuller F, Sander C, Sander R, Ries G, Classen M. Laser and afterloading radiation with iridium-192. In: Riemann JF, Ell C, eds. Lasers in gastroenterology. Stuttgart: Thieme Medical, 1989.

30 Loizou LA, Tobias J, Blackman G, Grigg D, Sargeant IR, Bown SG. Combined NdYAG laser phototherapy and external beam radiotherapy for the palliation of advanced malignant dysphagia. Br $\mathcal{Y}$ Cancer 1990; 62 (suppl $\mathrm{XI}): 28$

31 Oliver SE, Robertson CS, Logan RFA, Sokal M, Pearson JCG, Atkinson M. What does radiotherapy add to survival over endoscopic intubation alone in inoperable squamous cell oesophageal cancer? Gut 1990; 31: 750-2.

32 Flores AD. A review of radiotherapy of cancer of the oesophagus and cardia. Activity: Selectron Brachytherapy fournal, The Hague: 1989: Chapter 70. 